\title{
The Diagnosis Challenge of a Case of Spontaneous Heterotopic Pregnancy
}

\author{
Xiaoli Sun ${ }^{1}$, Tao Liü ${ }^{2}$, Chunmei Zhao ${ }^{1}$, Sanfeng Wang ${ }^{1}$ and Xiping Luo ${ }^{1 *}$ \\ ${ }^{1}$ Department of Gynecology, Guangdong Women and Children Hospital, China \\ ${ }^{2}$ Guangdong Provincial Institute of Public Health, China
}

Submission: February 11, 2017 ; Published: February 27, 2017

*Corresponding author: Xiping Luo, Department of Gynecology, Guangdong Women and Children Hospital, No. 521, Xingnan Road, Panyu District, Guangzhou 511442, China, Tel: 0086-020-39151752; Email: luoxiping07@ailyun.com

\begin{abstract} heterotopic pregnancy, which was diagnosed correctly with discretion and successfully treated by laparoscopic salpingectomy.

Keywords: Heterotopic pregnancy; Interstitial pregnancy; Spontaneous; Gestational trophoblastic neoplasia

Abbreviations: ART: Assisted Reproductive Technology; GTN: Gestational Trophoblastic Neoplasia
\end{abstract}

Heterotopic pregnancy was rare after natural conception, and easy to be missed or misdiagnosed. We present a case of spontaneous

\section{Introduction}

Heterotopic pregnancy refers to the simultaneous occurrence of two or more implantation sites, most of which are intrauterine pregnancy combined with ectopic pregnancy. Although the widely spread use of assisted reproductive technology (ART) increased the incidence of heterotopic pregnancy, it was rare after spontaneous pregnancy, with an estimated incidence of around 1:30,000 [1]. Few specific symptom or sign exists in early stage of heterotopic pregnancy, which caused misdiagnosis. Correct diagnose rely mostly on history, ultrasonography and HCG. Treatment of spontaneous heterotopic pregnancy includes medical treatment and surgery, while early diagnosis might avoid serious complications.

\section{Case Reports}

A 28-year-old patient presented to the gynecology department with a history of increasing HCG level at 24 days after suction of missed abortion. She was diagnosed as missed abortion at 47 days of natural pregnancy with HCG of 6219 IU/L. D \& C 2 days later found obvious villi which was confirmed by histology. The HCG level decreased to 3888 IU/L at 3 days after D\&C, but increased to $8325 \mathrm{IU} / \mathrm{L} 7$ days later. Both transvaginal ultrasound and hysteroscopic examination found no abnormal sign. On further monitor, the HCG level kept on increasing. A pelvic MRI examination found no mass in the uterus or in the abdomen. The patient had no vaginal bleeding or abdominal pain, and denied sexual life after D\&C.
The patient did laparoscopic salpingoplasty before because of primary infertility, and got pregnancy by IVF-ET, then delivered a baby by cesarean section 1 year ago because of macrosomia. But the pregnancy of missed abortion was conceived spontaneously. Doctors from an oncology center diagnosed as gestational trophoblastic tumor and suggested chemotherapy. She was reluctant to receive chemotherapy and referred to our hospital.

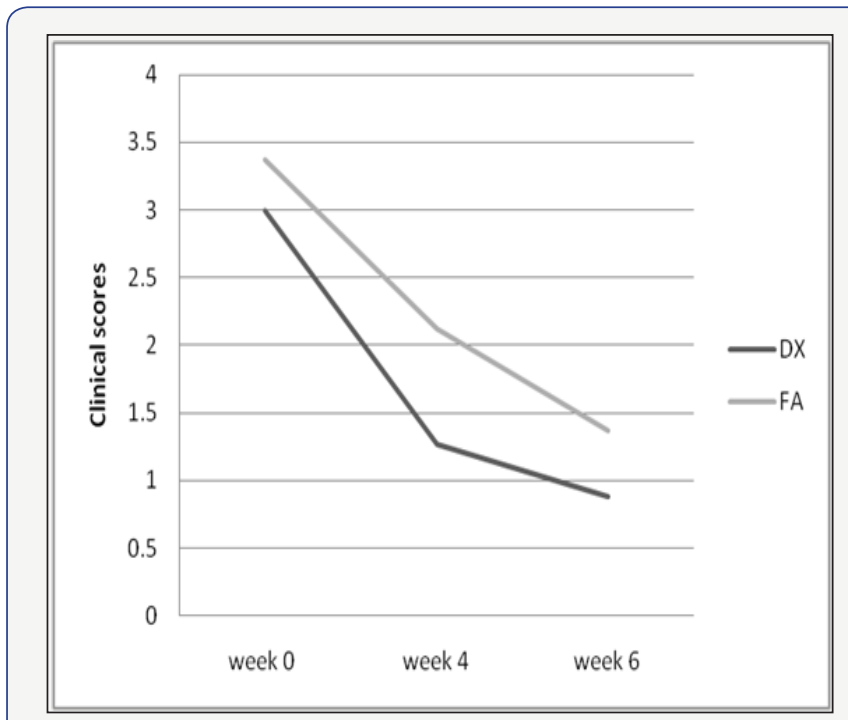

Figure 1: HCG value before and after missed abortion. 
On gynecologic examination, the uterus was in normal size without any mass in bilateral adnexal area. Transvaginal ultrasonography was repeated without any positive findings. Both chest ray and brain CT results were normal. HCG level decreased slowly in the following days (Figure 1). Although the abnormal high HCG level after missed abortion supported the diagnosis of gestational trophoblastic neoplasia (GTN), we supposed the HCG level should increase more rapidly if it was really a GTN. So we repeated transvaginal ultrasound examination again on 30 days after $D \& C$, which finally found a $3 \mathrm{~cm} \times 4 \mathrm{~cm}$ mass in the right cornua. Laparoscopy examination confirmed right interstitial pregnancy (Figure 2). A right-sided salpingectomy was performed. Histology confirmed an ectopic pregnancy. The patient recovered uneventfully after the operation.

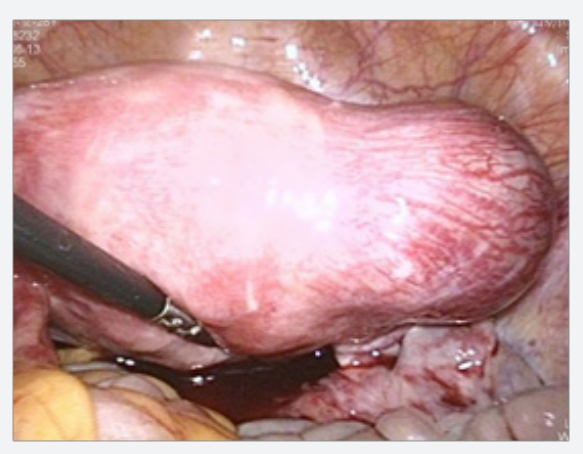

Figure 2: Laparoscopy examination indicated right interstitial pregnancy.

\section{Discussion}

Heterotopic pregnancy was rare. Risk factors of heterotopic pregnancy include ART, pelvic inflammatory disease, prior tubal surgery including salpingectomy and reconstructive tubal surgery [2].

Heterotopic pregnancy can have various presentations. It should be considered more likely

A. After assisted reproduction techniques.

B. With persistent or rising chorionic gonadotropin levels after dilatation and curettage for an induced or spontaneous abortion.

C. When the uterine fundus is larger than for menstrual dates.

D. With more than one corpus luteum.

E. With absence of vaginal bleeding in the presence of signs and symptoms of ectopic gestation and

F. When there is ultrasound evidence of uterine and extrauterine pregnancy [3].

Heterotopic pregnancy was easy to be missed or misdiagnosed. Except the reason of patients who did not visit doctors in early pregnancy, the main cause might be that gynecologists rely too much on ultrasound conclusion, while radiologists omit to scan the pelvic area carefully in the sign of intrauterine pregnancy. In a review of 82 cases of heterotopic pregnancy, 33\% of cases only simply reported a normal single or multiple intrauterine in a previous ultrasound scan. However, there was also the possibility that ectopic pregnancy did not grow as fast as intrauterine pregnancy which made it difficult to diagnose at early time. In unruptured and ruptured heterotopic pregnancy after ART, $66.7 \%$ and $85.7 \%$ cases were diagnosed by ultrasonography before 7 weeks of pregnancy respectively [4]. To date, there was no similar data concerning natural heterotopic pregnancy.

In our case, ultrasonography and pelvic MRI did not find the existence of ectopic pregnancy until 79 days of pregnancy. It might be easy to make a diagnosis of GTN and start chemotherapy in this case, as high HCG level persisted after missed abortion. Although no HCG monitoring guideline was recommended in GTN after non-molar pregnancy [5], from our experience we speculated that HCG should keep on increasing rapidly instead of slightly decreasing in the last week of surveillance. Thus, considering the prior tubal surgery history and the trend of HCG level, we preferred to monitor carefully instead of urgent chemotherapy. Finally, ectopic pregnancy mass was found. The successful diagnosis avoided chemotherapy and rupture of ectopic pregnancy at the same time.

\section{Conclusion}

Heterotopic pregnancy in natural conception was rare and had varied presentations. Correct diagnosis demands experienced and responsible doctors to make. Heterotopic pregnancy must be considered when HCG level did not decrease as expectantly after D\&C for an abortion. It is possible to monitor the HCG level cautiously instead of diagnosing GTN and starting chemotherapy in a short time.

\section{Conflict of Interest}

The authors report no declarations of interest.

\section{References}

1. Devoe R, Pratt J (1948) Simultaneous intrauterine and extrauterine pregnancy. American Journal of Obstetrics and Gynecology 56(6): $1119-1126$

2. Barrenetxea G, Barinaga RL, Lopez LA, Agirregoikoa JA, Mandiola M, et al. (2007) Heterotopic pregnancy: two cases and a comparative review. Fertility and Sterility 87(2): 9-15.

3. Cunningham FG (2001) Ectopic Pregnancy. In: Cunningham FG, et al. (Eds.), Williams Obstetrics. (21 ${ }^{\text {st }}$ edn), New York, USA, pp. 888-889.

4. Wang LL, Chen X, Ye DS, Liu YD, He YX, Guo W, et al. (2014) Misdiagnosis and delayed diagnosis for ectopic and heterotopic pregnancies after in vitro fertilization and embryo transfer. J Huazhong Univ Sci Technol Med Sci 34(1): 103-107.

5. Ngan HY, Seckl MJ, Berkowitz RS, Xiang Y, Golfier F, et al. (2015) Update on the diagnosis and management of gestational trophoblastic disease. International Journal of Gynecology and Obstetrics 131(2): S123-S126. 
This work is licensed under Creative Commons Attribution 4.0 Licens DOI: 10.19080/JGWH.2017.02.555594
Your next submission with Juniper Publishers will reach you the below assets

- Quality Editorial service

- Swift Peer Review

- Reprints availability

- E-prints Service

- Manuscript Podcast for convenient understanding

- Global attainment for your research

- Manuscript accessibility in different formats ( Pdf, E-pub, Full Text, Audio)

- Unceasing customer service

Track the below URL for one-step submission https://juniperpublishers.com/online-submission.php 